\title{
Challenges of Medical Text and Image Processing
}

\author{
Iswanto Iswanto, M. Ilayaraja, K. Shankar, Phong Thanh Nguyen, Satria Abadi
}

\begin{abstract}
The processing of medical image has encountered sensational development, and its researching is doing by almost every field of engineering or medical sciences like designing, insights, material science, science and medication. CADxprocessing has recently transformed into a critical bit of clinical day by day practice. Joined by a flood of new headway of high advancement and use of various imaging modalities, more challenges develop; for example, how to process and separate a basic volume of images with the objective that splendid information can be conveyed for ailment ends and treatment. Thusly, the inside steps of image examination, to be explicit: include extraction, division, order, quantitative estimations, and translation are displayed in sperate portions. Because of its high importance, the attention is on division of biomedical image. Remarkable division methodologies and strategies have been made in the medical application zone. The principle goals of this paper are to give a preamble to crucial thoughts and frameworks for medicinal image taking care of and to propel interests for further assessment and research in medical imaging handling. We will display the Medical Image Processing and layout related research work around there.
\end{abstract}

Keywords : Segmentation, MRI, Visualization, Biomedical Image Processing.

\section{INTRODUCTION}

Numerical models are the foundation of biomedical handling. Assembling those models as for data isolated from images continues being a foremost strategy for achieving consistent progression in preliminary, clinical, biomedical, and conduct explore. This paper may enable us to get to know the essentials of restorative picture preparing, establishment it as a plastic mix of science and craftsmanship, or all the more all value a legitimate objective in therapeutic picture medicinal services of - helping patients. We outlined in this paper some basic applications in therapeutic picture preparing. Consequently, the center strides of picture assessment, unequivocally: incorporate extraction, division, gathering, quantitative estimations, and interpretation are appeared in isolated zones. Because of its high centrality, the

Revised Manuscript Received on July 22, 2019.

* Correspondence Author

Iswanto Iswanto, Department of Engineer Profession Program, Universitas Muhammadiyah Yogyakarta, Yogyakarta, Indonesia. E-mail: iswanto_te@umy.ac.id

M. Ilayaraja, Department of Computer Science and Information Technology, Kalasalingam Academy of Research and Education, Krishnankoil, India.

K. Shankar*, Department of Computer Applications, Alagappa University, Karaikudi, India. E-mail: shankarcrypto@gmail.com

Phong Thanh Nguyen*, Department of Project Management, Ho Chi Minh City Open University, Vietnam. E-mail: phong.nt@ou.edu.vn

Satria Abadi, Department of Information Systems, STMIK Pringsewu, Lampung, Indonesia. emphasis is on division of biomedical pictures. Wonderful division frameworks and techniques have been made in the restorative application zone. We will show the Medical Image Processing and related research work. The electronic transmission and trade of restorative pictures will wind up being ceaselessly basic in future for sight and intelligent interactive media applications, for example, electronic patient records in prosperity telematics and fused thought. We wrap up by raising assessment issues and proposing future headings for further improvements Today, medicinal images are procured by a scope of methods over every biological scale, which go a long ways past the unmistakable light photos and magnifying instrument images of the mid twentieth century. Present day medical images may be seen as geometrically composed assortments of data tests which assess such varying physical ponders as the time assortment of hemoglobin deoxygenating during neuronal digestion, or the spread of water particles through and inside tissue. The broadening degree of imaging as a way to deal with make our observations out of the biophysical world has incited a shocking augmentation in our ability to apply new taking care of systems and to merge various channels of data into cutting edge and complex logical models of physiological capacity and dysfunction.

Medical image handling manages the improvement of issue explicit ways to deal with the upgrade of rawmedicalimage information for the motivations behind specific perception just as further research. There are various subjects in medical imageprocessing: some underscore general important speculation and some accentuation on unequivocal applications. We by and large revolve around image division and multi-spectral investigation. image division: Image division is portrayed as a partitioning of aimage into area that are critical for a specific task; it is a checking issue. This may, for instance, incorporate the disclosure of a brain tumor from MR or CT images (Fig. 1).

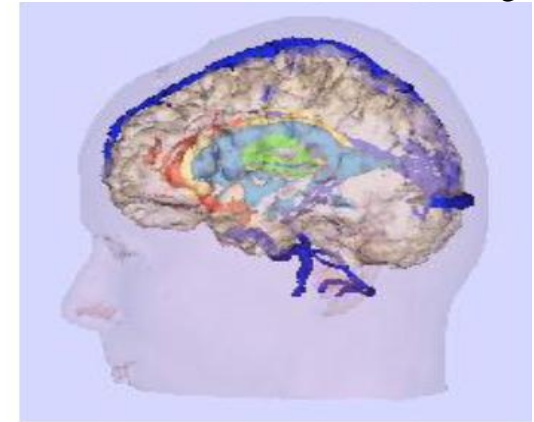

Figure 1: An 3d architecture of medical image which shows the mri data of brain 


\section{Challenges of Medical Text and Image Processing}

Division is one of the underlying advances inciting image assessment and comprehension. The goal is definitely not hard to state, yet difficult to achieve correctly.

\section{IMAGE PROCESSING}

The medical image processing in the medicinal strategy, and to respect the present image utilization beforehand, during, and after treatment, we revolve our assessment around four key pieces of image guided treatment (IGT) and image guided surgery (IGS): confinement, focusing on, checking, and control. Specifically, in medicinal imaging we have four key issues:

\section{1) Medical Image Segmentation}

The segmentation of medical image can be refer to divide the image into parts. These image parts known as segmentation and further can be used as input for feature extraction and medical use.

\section{2) Image Registration}

In this process the extracted features of the images are indexed so that some meaningful data can be extracted.

\section{3) Visualization}

In this process the medical image guided methods are exposed;

\section{4) Simulation}

The image process algorithms are applied and the useful information is extracted.

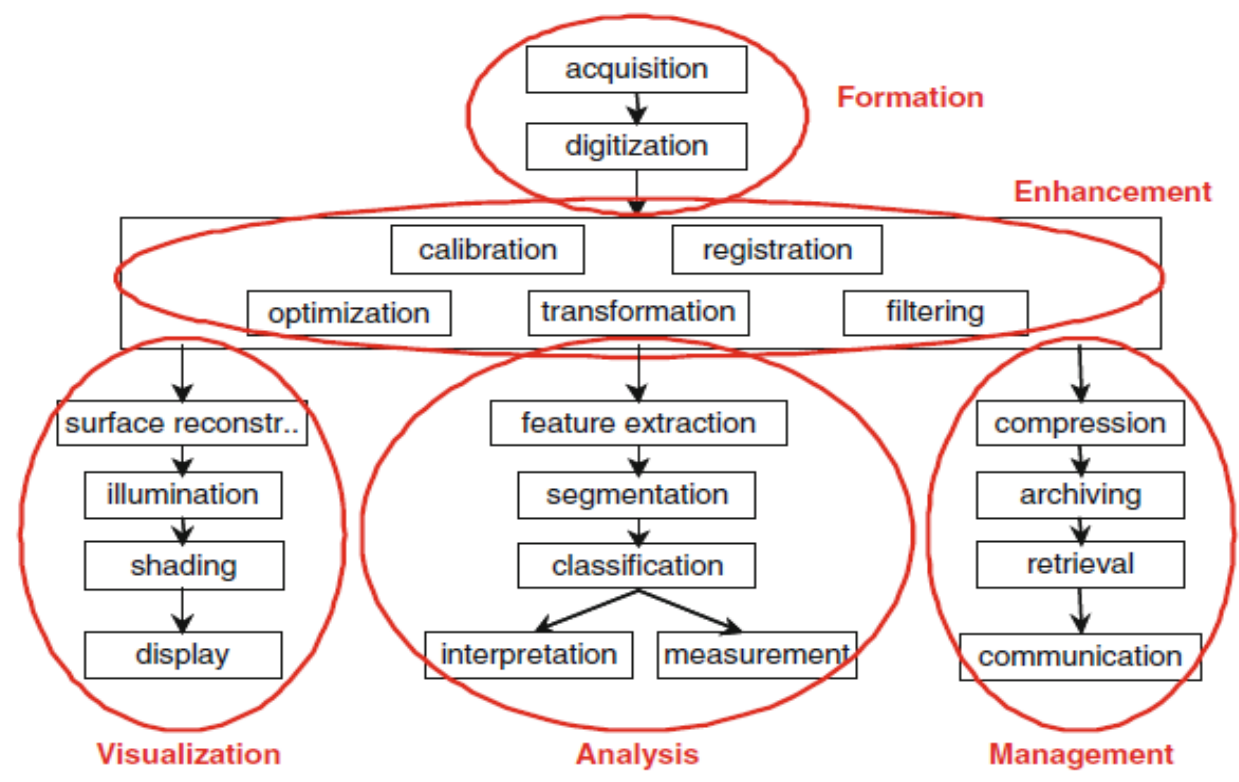

FIGURE 2. MODULES OF IMAGE PROCESSING.

\section{Medical Image Processing in Detail}

The consistently used term "medical image processing" means the making ready of automated image dealing with for biomedical sciences. At the point when all is said in done, propelled image handling covers four essential domains (Fig. 2):

1. Image arrangement fuses all of the methods from getting the image to confining an advanced image lattice.

2. Image representation alludes to a wide range of control of this matrix, realizing an upgraded yield of the image.

3. Image examination have every one of the means of processing, which are used for quantitative estimations similarly as unique explanations of biomedical images.

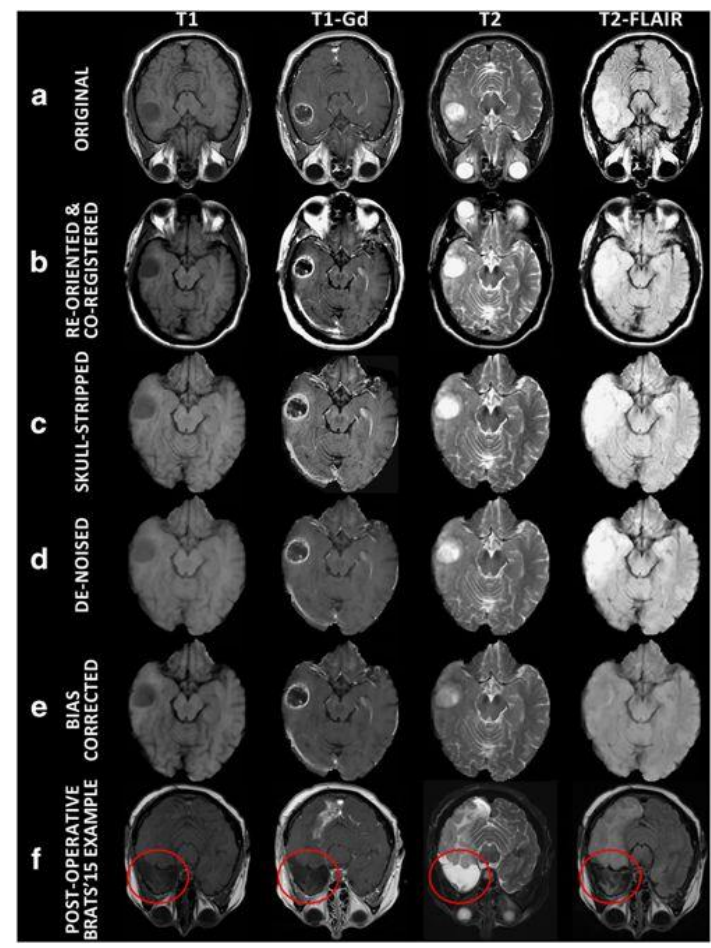

Figure 2. Detailed medical image processing with mri brain images. 
These methods require from the prior learning on the nature and substance of the images, which must be coordinated into the procedure on abnormal state of reflection. As such, the method of image assessment is indisputable, and made procedure can be moved every so often direct into other application area.

4. Image the official's wholes up all systems that give the proficient stockpiling, communication, transmission, chronicling, and get to (recovery) of image information. In this manner, the strategies for telemedicine are in like manner a bit of the image management.

Instead of image examination, which is often also insinuated as irregular state image processing, low-level dealing with methods manual or customized strategies, which can be recognized without from the prior data on the specific substance of images. This kind of procedure has tantamount effects paying little personality to the substance of the images. For example, histogram stretching out of a radiograph improves the distinction as it does on any event photograph. Thusly, low-level handling of procedures are commonly available with activities for image update.

\section{Biomedical Image Processing}

A specific issue in high level processing of biomedical images is intrinsically evident: coming about because of its perplexing nature, it is hard to figure medical from the earlier learning to such an extent that it very well may be incorporated legitimately and effectively into programmed procedure of image handling. In the composition, this is suggested as the semantic hole, which means the disparity between the intellectual elucidation of a symptomatic image by the doctor (high state) and the basic structure of discrete pixels, which is utilized in PC projects to speak to a image (low level). In the medical zone, there are three principal perspectives obstructing spreading over this opening:

Table 1. The steps acquired for medical image processing

\begin{tabular}{|c|c|}
\hline Heterogeneity of images: & $\begin{array}{l}\text { Medical images show living tissue, organs, or body parts. } \\
\text { Notwithstanding whether got with a comparable strategy and } \\
\text { following an organized verifying show, shape, size, and internal } \\
\text { structures of these things may change strikingly not simply from } \\
\text { patient to determined (between subject assortment) yet also among } \\
\text { different points of view on a patient and practically identical } \\
\text { viewpoints on comparative patients at different time (intra-subject } \\
\text { assortment). By the day's end, natural structures are obligated to both } \\
\text { between and intra-individual alterability. Thusly, comprehensive } \\
\text { itemizing of from the previous learning is boundless }\end{array}$ \\
\hline Unknown delineation of objects & $\begin{array}{l}\text { Frequently, biomedical structures can't be isolated from the foundation } \\
\text { in light of the fact that the indicatively or medically significant article } \\
\text { is spoken to by the whole image. Regardless of whether determinable } \\
\text { articles are seen in biomedical images, their division is risky on the } \\
\text { grounds that the shape or marginal itself is spoken to fuzzily or just } \\
\text { mostly. Consequently, medicalally related things frequently can be } \\
\text { disconnected all things considered on the texture level. }\end{array}$ \\
\hline Robustness of algorithms & $\begin{array}{l}\text { In spite of these regular properties of medicinal pictures, which } \\
\text { frustrate their abnormal state dealing with, remarkable basics of loyal } \\
\text { quality and force of restorative methods and, when related in associated } \\
\text { in calendar, imageprocessing system are also referenced in the } \\
\text { therapeutic field. Standard talking, altered appraisal of pictures in } \\
\text { prescription ought not give wrong estimations. That surmises that } \\
\text { pictures, which can't be managed effectively, must be in this manner } \\
\text { named such, rejected and pulled once again from further dealing with. } \\
\text { Likewise, all pictures that have not been rejected must be assessed } \\
\text { sufficiently. Furthermore, the measure of rejected pictures isn't } \\
\text { permitted to wind up being colossal, since most therapeutic imaging } \\
\text { systems are damaging and can't be repeated in perspective on picture } \\
\text { preparing botches. }\end{array}$ \\
\hline
\end{tabular}




\section{CLASSIFICATION OF IMAGE SEGMENTATION}

Image division approaches can be masterminded by both the component and the kind of frameworks used. Component incorporate pixel intensities, edge data, and surface, and so forth. Methodology reliant on these component can be completely requested into structure and statistical procedures.

\section{- Structural Methods}

Essential methodologies rely upon the spatial properties of the image, for instance, edges and regions. Distinctive edge revelation procedure have been associated with independent cutoff points between different brain tissues. Region creating is another outstanding basic technique. In this approach, one begins by isolating aimage into little areas, which can be considered as "seeds". By then, all points of confinement between contiguous areas are analyzed. Solid limits (the extent that specific properties) are kept, while frail limits are rejected and the neighboring region mixed. The technique is finished iteratively until no restrictions are slight enough to be rejected.

Be that as it may, the exhibition of the strategy relies upon seed choice and whether the regions are all around characterized, and in this way is likewise not thought about robust.

\section{- Statistical Methods}

Factual methods name pixels as appeared by likelihood esteems which are settled reliant on the power appointment of the picture. Dark level thresholding is the most direct, yet reliably viable, division methodology. In this methodology, structures in the picture are alloted an engraving by differentiating their Gray-level an impetus with in any event one power limits. A solitary edge serves to area the picture into only two districts, a foundation and a closer view. Now and again the task of picking a point of confinement is extremely basic, when there is a sensible qualification between the Gray-levels of the articles we wish to divide.

\section{CHALLENGES IN MEDICAL IMAGE PROCESSING}

Useful modalities, then again, delineate the metabolism of the underlying tissues or organs. They incorporate the three atomic prescription modalities, specifically, scintigraphy, single photon emission computed tomography (SPECT) and positron emission tomography (PET) just as functional magnetic resonance imagery (FMRI). For all intents and purposes all images are directly obtained cautiously and joined in a modernized image archiving and communication system (PACS).

There are different unequivocal troubles in medicinal image processing. They are;

- Image update and recovery

- Automated and definite division of highlight of intrigue
- Automated and definite registration and combination of multimodality images

- Classification of image include, to be explicit depiction and making out of structures

- Quantitative estimation of image include and a translation of the estimations

- Development of incorporated structures for the clinical division

\section{CONCLUSION}

We believe that this paper may empower us to get acquainted with the fundamentals of medical image processing, foundation it as a plastic blend of science and craftsmanship, or more all appreciate an authoritative goal in medical image health care of - helping patients. We illustrated in this paper some critical applications in medicinal image processing. Thusly, the middle steps of image examination, explicitly: include extraction, division, grouping, quantitative estimations, and translation are shown in segregated zones. Due to its high significance, the accentuation is on division of biomedical images. Phenomenal division systems and methods have been made in the medical application zone. We will exhibit the Medical Image Processing and related research work. The electronic transmission and exchange of medical images will end up being continuously critical in future for sight and interactive multimedia applications, for instance, electronic patient records in wellbeing telematics and incorporated consideration. We finish up by raising examination issues and proposing future headings for further enhancements.

\section{ACKNOWLEDGMENT}

This article has been written with financial support of RUSA-Phase 2.0 grant sanctioned vide Letter No. F. 24-51/2014-U, Policy (TNMulti-Gen), Dept. of Edn. Govt. of India, Dt. 09.10.2018.

\section{REFERENCES}

1. Handels H, Meinzer HP, Deserno TM, Tolxdorff T (2010) Advances and recent developments in medical image computing. IntJ Comput Assist Radiol Surg. doi:10.1007/s11548-010-0540-6

2. Hansen C, Johnson C (2004) The visualization handbook. Elsevier,Amsterdam

3. Haux R (2006) Health information systems. Past, present, future.Int J Med Inform 75:268-281

4. Long LR, Antani S, Deserno TM, Thoma GR (2009) Contentbasedimage retrieval in medicine. retrospective assessment, stateof the art, and future directions. Int J Health Inform SystInformat4(1):1-16

5. Manjunath BS, Sumengen B, Bi Z, Byun J, El-Saban M, FedorovD, Vu N (2006) Towards automated bioimage analysis: from featuresto semantics. In: Proc IEEE IntSymp Biomed Imaging, pp255-258

6. Meijering E, Smal I, Danuser G (2006) Tracking in molecularbioimaging. IEEE Signal Process Mag 23(3):46-53

7. Müller H, Michoux N, Bandon D, Geissbuhler A (2004) A reviewof content-based image retrieval systems in medical applications.Clinical benefits and future directions.Int J Med Inform 73(1):1-23

8. Névéol A, Deserno TM, Darmonic SJ, Güld MO, Aronson AR(2009) Natural language processing versus content-based imageanalysis for medical document retrieval. J Am SocInfSciTechnol60(1):123-134 
9. de Oliveira JEE, Machado AMC, Chavez GC, Lopes APB, DesernoTM, Araujo A (2010) Mammosys: a content-based image retrieval system using breast density patterns. Comput MethodsPrograms Biomed 99(3):289-297

10. Palm C, Axer M, Grässel D, Dammers J, Lindemeyer J, Zilles L(2010) Towardsultra-high resolution fibre tract mapping of the humanbrain: registration of polarised light images and reorientationof fibre vectors. Front Human Neurosci 4(9):1-16

11. Papenberg N, Bruhn A, Brox T, DidasS,Weickert J (2006) Highlyaccurate optic flow computation with theoretically justified warping.Int J Comput Vis 67(2):141-158

12. Qi H, Snyder WE (1999) Content-based image retrieval in imagearchiving and communications systems. J Digit Imaging 12(2):81-83

13. Dougherty D. Digital Image Processing for Medical Applications. Cambridge:Cambridge University Press; 2009. ISBN: 0-521-86085-7

14. Dougherty ER (ed). Digital Image Processing Methods. New York: CRC Press;1994. ISBN: 978-0-824-78927-5

15. Guy C, Ffytche D. Introduction to the Principles of Medical Imaging. London:Imperial College Press; 2005. ISBN: 1-860-94502-3

16. Jan J. Medical Image Processing, Reconstruction and Restoration: Concepts andMethods. Boca Raton: CRC Press; 2005. ISBN: $0-824-75849-8$

17. Kim Y, Horii SC (eds). Handbook of Medical Imaging. Vol. 3: Display and PACS.Bellingham: SPIE Press; 2000. ISBN: 0-819-43623-2

18. Meyer-Baese A. Pattern Recognition in Medical Imaging. San Diego: AcademicPress; 2003. ISBN: 0-124-93290-8

19. Preim B, Bartz D. Visualization in Medicine. Theory, Algorithms, and Applications.Amserdam: Morgan Kaufmann; 2007. ISBN: 978-0-123-70596-9Rangayyan RM. Biomedical Image Analysis. New York: CRC Press; 2005. ISBN:0-849-39695-6 